\title{
Effect of Aspirin on Thrombin-Induced Adherence of Platelets to Cultured Cells from the Blood Vessel Wall
}

\author{
Robert L. Czervionke, John C. Hoak, and Glenna L. Fry, Division of \\ Hematology-Oncology, Department of Medicine and the Cardiovascular Center, \\ University of lowa, Iowa City, Iowa 52242
}

A B S T RA C T An in vitro method was used to detect adherence of ${ }^{51} \mathrm{Cr}$-labeled platelets to monolayers of cultured human endothelial, fibroblast, and smooth muscle cells. Washed platelets did not adhere to untreated or aspirin-treated endothelial monolayers in the absence of thrombin. In contrast, thrombin-induced platelet aggregates adhered to all of the monolayers but adherence to endothelium was significantly less than to the other cells. Additional evidence for adherence of platelets to the endothelium was provided by scanning and transmission electron microscopy. Thrombin-induced platelet adherence to endothelium was inhibited by hirudin. Platelet adherence induced by thrombin was enhanced significantly by treatment of the endothelial monolayer with $1-2 \mathrm{mM}$ aspirin. This increase in adherence was seen even when aspirin-treated platelets were used; adherence values approached those seen with fibroblasts and smooth muscle cells. An aspirin concentration of $0.1 \mathrm{mM}$ was sufficient to block thrombin-induced malonaldehyde production in platelets but it did not interfere with the inhibitory effect of the endothelium against platelet adherence. The effect of aspirin on the endothelium was temporary and inhibitory activity of the endothelium wias restored $1 \mathrm{~h}$ after aspirin had been removed from the incubation system. The ability of thrombin to cause adherence of platelets to undamaged endothelium, and the potential for aspirin to enhance this adherence have implications for mechanisms which operate in platelet interaction with the blood vessel wall.

This work was presented in part at the 20th Annual Meeting of the American Society of Hematology, San Diego, Calif. on 6 December 1977 and at the Meeting of the Central Society for Clinical Research, Chicago, Ill. on 3 November 1977.

Dr. Hoak was the recipient of Research Career Development Award K3-HL-19,370-10 from the National Heart, Lung, and Blood Institute.

Received for publication 19 October 1977 and in revised form 16 June 1978.

\section{INTRODUCTION}

The interaction of platelets with the vessel wall plays an important role in hemostasis and in the development of thrombotic lesions. The capacity of platelets to adhere to the subendothelial structures after denudation of the endothelium, has been adequately demonstrated (1-6) and is generally accepted. Less understood is the ability of platelets to adhere to the intact endothelium either as a consequence of altered flow characteristics, endothelial injury without detachment, or the effect of procoagulants (7-10).

To study the effect of procoagulants on platelet-vessel wall interactions, a modification of the in vitro model system reported by Winkelhake and Nicolson (11) was employed to delineate the adherence capabilities of the various cells which compose the vessel wall. In the present study endothelial cells from the umbilical vein, and smooth muscle cells and fibroblasts from the umbilical artery were used. This report details the adhesive properties of ${ }^{51} \mathrm{Cr}$-labeled platelets to these cell monolayers as a consequence of incubation of the platelets with thrombin. The results indicate that platelet aggregates are much more adherent to smooth muscle cells or fibroblasts, the subendothelial cellular components, than they are to the endothelium. Of particular interest was the demonstration that thrombin had the potential to cause platelets to adhere to the undamaged endothelium and that this effect was enhanced by treatment of the endothelium with aspirin.

\section{METHODS}

Reagents. Powdered medium 199 (with Earle's salts, with L-glutamine, without $\mathrm{NaHCO}_{3}$ ), Hanks' balanced salt solution $(10 \times)$, Eagle's basal medium vitamin solution $(100 \times)$, Eagle's basal medium amino acids solution $(100 \times)$, and calcium and magnesium-free Dulbecco's phosphate-buffered saline (PBS) ${ }^{1}$

${ }^{1}$ Abbreviations used in this paper: ACD, acid citrate dextrose anticoagulant; ASA, acetylsalicylic acid or aspirin; FCS, 
were purchased from Grand Island Biological Co., Grand Island, N. Y. Human thrombin prepared by activation of prothrombin with citrate, Trizma base (Tris), Hepes buffer, hirudin (Grade II), and EDTA were obtained from the Sigma Chemical Co., St. Louis, Mo. Sodium chromate ${ }^{51} \mathrm{Cr}$, was purchased from E. R. Squibb \& Sons, Princeton, N. J. Sodium heparin was purchased from Abbott Diagnostics, North Chicago, Ill. Topical bovine thrombin was obtained from Parke, Davis \& Co., Detroit, Mich. Highly purified human thrombin, prepared by activation of prothrombin with Taipan snake venom (12), was kindly provided by Dr. Whyte Owen, University of Iowa. Fetal calf serum (FCS) was obtained from Reheis Co., Inc., Kankakee, Ill. Pentex bovine serum albumin, fraction V, fatty acid-poor, was obtained from Miles Laboratories, Inc., Kankakee, Ill. Aspirin, acetylsalicylic acid (ASA), was from Mallinckrodt Inc., St. Louis, Mo. All other chemicals were of reagent grade.

Culture supplies. Culture flasks, Petri dishes, and plastic centrifuge tubes were purchased from Falcon Plastics, Division of BioQuest, Oxnard, Calif.

Solutions. Modified medium 199 (MM-199): $9.87 \mathrm{~g} / \mathrm{liter}$ medium 199 powder, $10 \mathrm{ml} /$ liter $\mathrm{BME}$ vitamin solution $(100 \times), 10 \mathrm{ml} /$ liter BME amino acids solution $(100 \times), 1 \mathrm{~g} /$ liter glucose, $0.1 \mathrm{~g} /$ liter Neomycin, $2.2 \mathrm{~g} /$ liter $\mathrm{NaHCO}_{3}, \mathrm{pH} 7.3-$ 7.4. MM-199 with $20 \%$ FCS: Mix eight parts MM-199 with two parts FCS. Modified Hanks' balanced salt solution (MHBSS): Hanks' balanced salt solution without $\mathrm{NaHCO}_{3}$, $15 \mathrm{mM}$ Hepes, pH 7.4. Incubation medium (IM): $8.6 \mathrm{~g} / \mathrm{liter}$ bovine serum albumin, $140.3 \mathrm{mM} \mathrm{NaCl}, 5.8 \mathrm{mM} \mathrm{KCl}, 2.7 \mathrm{mM}$ $\mathrm{CaCl}_{2}, 16.3 \mathrm{mM}$ Tris, $\mathrm{pH}$ 7.40. $2 \mathrm{mM}$ ASA in IM, pH 7.40: ASA was dissolved in IM, pH 7.47, immediately before use. Other concentrations of ASA in IM were diluted from this stock with IM, pH 7.40. Tyrode's solution: The second washing solution defined by Mustard et al. (13) with the modification that apyrase was omitted from the preparation. $2 \mathrm{mM}$ ASA in Tyrode's solution, pH 7.40: ASA was dissolved in Tyrode's solution, $\mathrm{pH} 7.45$, immediately before use. Dilutions from this stock solution were made with Tyrode's solution, $\mathrm{pH} 7.40$.

Isolation and culture of cells. Primary cultures of human endothelial cells were prepared from human umbilical veins according to a slight modification of the method of Jaffe et al. (14). Cells were suspended in MM-199 with $20 \%$ FCS, seeded in $35 \times 10-\mathrm{mm}$ Petri dishes, and incubated in a $5 \% \mathrm{CO}_{2}$ atmosphere at $37^{\circ} \mathrm{C}$. After $24 \mathrm{~h}$, the monolayers were washed with fresh MM-199 with $20 \%$ FCS, and then relayered with $2 \mathrm{ml}$ of the same medium. Confluent primary human endothelial monolayers, containing 0.7-0.8 $\times 10^{6}$ cells, were used for adherence studies four days after seeding. Cell counts were determined with a hemocytometer after suspension of the cells with $0.25 \%$ trypsin- $0.05 \%$ trisodium EDTA in PBS (pH 7.4).

Monolayers of arterial fibroblasts were prepared by mincing umbilical arteries. Into $75-\mathrm{cm}^{2}$ tissue culture flasks, $1-2-\mathrm{mm}$ pieces of artery were placed with a small amount of MM-199 with $20 \%$ FCS. The cells which grew out within 2.5 wk were removed by treatment for $3 \mathrm{~min}$ at $37^{\circ} \mathrm{C}$ with $0.25 \%$ trypsin$0.05 \%$ trisodium EDTA. Fibroblasts in sufficient numbers to seed $35 \times 10-\mathrm{mm}$ Petri dishes were obtained after serial passages in MM-199 with $20 \%$ FCS. A confluent monolayer of fibroblasts contained $0.3-0.4 \times 10^{6}$ cells per $35 \times 10-\mathrm{mm}$ Petri dish.

To obtain smooth muscle cells umbilical arteries were first

fetal calf serum; IM, incubation medium; MDA, malonaldehyde; MHBSS, modified Hanks' balanced salt solution; MM-199, modified medium 199; PBS, phosphate-buffered saline; $\mathbf{P G I}_{2}$, prostaglandin $\mathrm{I}_{2}$ or prostacyclin. perfused with $0.2 \%$ collagenase for $6 \mathrm{~min}$. The artery was opened and the remainder of the vessel wall was lifted with a gill knife. This tissue was minced and stirred with either $0.2 \%$ collagenase or $0.25 \%$ trypsin for $30 \mathrm{~min}$. After filtration through gauze the resulting suspension was centrifuged and the cell pellet was resuspended in MM-199 with $20 \%$ FCS, and recentrifuged. The resulting pellet was resuspended in the same medium and seeded in a 75- $\mathrm{cm}^{2}$ tissue culture flask which was incubated at $37^{\circ} \mathrm{C}$ in a $5 \% \mathrm{CO}_{2}$ atmosphere. Cells were removed from the confluent flask after treatment for 3 min at $37^{\circ} \mathrm{C}$ with $0.25 \%$ trypsin- $0.05 \%$ EDTA. After serial passage a sufficient quantity of predominantly smooth muscle cells was obtained and used to seed $35 \times 10-\mathrm{mm}$ Petri dishes. A confluent dish contained 0.5-0.7 $\times 10^{6}$ smooth muscle cells.

Endothelium, fibroblasts, and smooth muscle cells were differentiated by phase microscopy and their ultrastructure was monitored with transmission electron microscopy. Cell identification was consistent with the published criteria for these types of cells (14-16). Empty dish controls consisted of $35 \times 10-\mathrm{mm}$ Petri dishes which were incubated with MM199 with $20 \%$ FCS and handled exactly as dishes containing cells.

Preparation of labeled, washed platelet suspensions. The isolation and washing of platelets was a modification of the procedure described by Mustard et al. (13). Venous blood was taken from normal, nonfasting human donors who had not taken aspirin or other antiplatelet drugs for 10 days and, in the case of women, were not using oral contraceptives. Five parts blood was mixed with one part of the acid citrate dextrose (ACD) anticoagulant of Aster and Jandl (17). 100 ml blood, mixed with $20 \mathrm{ml} \mathrm{ACD}$, was centrifuged in $40 \mathrm{ml}$ siliconized centrifuge tubes at $325 \mathrm{~g}$ for $15 \mathrm{~min}$ and the resulting platelet-rich plasma was separated. The platelet-rich plasma was centrifuged at $1,000 \mathrm{~g}$ for $15 \mathrm{~min}$ and the platelet pellet was resuspended in $10 \mathrm{ml}$ of the above-defined Tyrode's solution and $0.4 \mathrm{ml} \mathrm{ACD}$. If aspirin-treated platelets were required, the Tyrode's solution contained aspirin and a platelet number not exceeding $1.5 \times 10^{9}$ platelets $/ \mathrm{ml}$. After the addition of $250 \mathrm{U}$ heparin and $100 \mu \mathrm{Ci} \mathrm{Na}{ }_{2}{ }^{51} \mathrm{CrO}_{4}(0.5-1.0$ $\mathrm{ml}$ ) the platelet suspension was incubated at $37^{\circ} \mathrm{C}$ for $20 \mathrm{~min}$. The pellet resulting from centrifugation at $650 \mathrm{~g}$ for $10 \mathrm{~min}$ was resuspended in $10 \mathrm{ml}$ Tyrode's solution and $0.4 \mathrm{ml} \mathrm{ACD}$, and then recentrifuged at $650 \mathrm{~g}$. Platelets were resuspended in a second washing solution which consisted of $10 \mathrm{ml} \mathrm{Ty-}$ rode's solution and $0.2 \mathrm{ml}$ ACD. A final centrifugation at $650 \mathrm{~g}$ yielded a pellet which was resuspended in $9 \mathrm{ml}$ Tyrode's solution. $0.5 \mathrm{ml}$ of this labeled platelet suspension contained $\cong 15,000-20,000 \mathrm{cpm}$ of ${ }^{51} \mathrm{Cr}$ radioactivity and $5-7 \times 10^{8}$ platelets. As determined by phase microscopic examination, platelet suspensions were free of aggregates. Suspensions were stored at $37^{\circ} \mathrm{C}$ if not immediately used but in all cases were incubated with the cell monolayers not later than $4 \mathrm{~h}$ after the blood was drawn. Platelets did not aggregate spontaneously during this period.

Aggregation studies. Control studies with a Payton aggregation module (Payton Associates, Buffalo, N. Y.) were performed at the same time that suspensions were incubated with the thrombin treated monolayer. Thrombin, at a final concentration of $0.06 \mathrm{U} / \mathrm{ml}$, was used to aggregate both untreated or aspirin-treated platelets suspended in Tyrode's solution with IM.

Malonaldehyde (MDA) assay. Aliquots of the initial ACD platelet-rich plasma and the final platelet wash suspension were immediately assayed. Platelets were resuspended in $1.5 \mathrm{ml}$ of $0.5 \mathrm{U} / \mathrm{ml}$ bovine thrombin in PBS or $1.5 \mathrm{ml}$ PBS (control). MDA was determined by the method of Stuart et al. (18), with the modification that $1.5 \mathrm{ml}$ thiobarbituric acid solution was employed. 
After MDA assay the tube containing platelets and MDA reagents was centrifuged at $1,100 \mathrm{~g}$ for $15 \mathrm{~min}$. The resulting platelet pellet was washed with $5 \mathrm{ml}$ PBS, recentrifuged, and solubilized with $1.0 \mathrm{~N} \mathrm{NaOH}$. Protein was determined by the procedure of Lowry et al. (19) and was converted to platelet count by the factor $1 \times 10^{9}$ platelets $/ 1.7 \mathrm{mg}$ protein $(20)$. MDA was normalized to nanomoles $/ 10^{9}$ platelets. Thrombin stimulated MDA equals MDA (thrombin platelets) minus MDA (control platelets).

Adherence of preformed platelet aggregates to cell monolayers. $1 \mathrm{ml} \mathrm{IM}$ and $0.5 \mathrm{ml}{ }^{51} \mathrm{Cr}$-platelets in Tyrode's solution were stirred in the Payton aggregation module at 1,000 $\mathrm{rpm}$ and $37^{\circ} \mathrm{C}$ for $3 \mathrm{~min}$. $25 \mu \mathrm{l} \mathrm{IM} \mathrm{(control)} \mathrm{or} 25 \mu \mathrm{l} 4 \mathrm{U} / \mathrm{ml}$ bovine thrombin in IM was added to the platelet suspension and aggregation was monitored on the strip chart recorder. As soon as maximal aggregation was indicated the platelets were poured onto the cell monolayer, which had been washed previously with two 1.5-ml portions of MHBSS. In additional studies the excess thrombin was first neutralized by stirring the aggregated platelets in the cuvette with $25 \mu \mathrm{l} 4 \mathrm{U} / \mathrm{ml}$ hirudin for $1 \mathrm{~min}$ before transfer to the monolayer. The 35 $\times 10$-mm Petri dish, containing the cell monolayer and platelet suspension, was placed in a $37^{\circ} \mathrm{C}$ metabolic incubator on a rocker platform with a $30^{\circ}$ tilt (Bellco Glass Inc., Vineland, N. J.) and rocked continuously at a rate of 10 up-and-down cycles per min. After $30 \mathrm{~min}$ incubation the suspension containing unattached platelets was transferred to a plastic centrifuge tube. After the addition of $1.5 \mathrm{ml}$ MHBSS solution the dish was returned to the rocker for $5 \mathrm{~min}$. This $1.5-\mathrm{ml}$ MHBSS solution and an additional 1-ml MHBSS wash (no rocking) were placed in the centrifuge tube containing the unattached platelets. After centrifugation at $1,000 \mathrm{~g}$ for $10 \mathrm{~min}$, ${ }^{51} \mathrm{Cr}$ radioactivity in the tube was immediately counted with an Abbott model 111A gamma counter (Abbott Diagnostics).

The amount of radioactivity remaining with the cell monolayer was determined by solubilizing the cell monolayer and attached platelets with $1.5 \mathrm{ml} 2 \% \mathrm{Na}_{2} \mathrm{CO}_{3}$ in $0.1 \mathrm{~N} \mathrm{NaOH}$. After solubilization this solution and a l-ml wash were combined in a plastic centrifuge tube and ${ }^{51} \mathrm{Cr}$ radioactivity was determined. Percent adherence was calculated by dividing monolayer counts per minute by total counts per minute added to the dish, $\times 100$.

Adherence of platelets to monolayers previously treated with thrombin. The cell monolayer was washed twice with $1.5 \mathrm{ml}$ MHBSS. $1 \mathrm{ml}$ IM (control) or $1 \mathrm{ml}$ thrombin in IM was placed on the monolayer and the Petri dish was incubated without rocking for $5 \mathrm{~min}$ at $37^{\circ} \mathrm{C}$. The preincubation solution was left on the monolayer and $0.5 \mathrm{ml}{ }^{51} \mathrm{Cr}$-platelets in Tyrode's solution was immediately added to the $35 \times 10-\mathrm{mm}$ Petri dish, which then was rocked at $37^{\circ} \mathrm{C}$ for $30 \mathrm{~min}$ and handled as described above for adherence with thrombininduced preformed platelet aggregates.

Adherence of platelets to monolayers treated with aspirin. The monolayer was washed twice with $1.5 \mathrm{ml}$ MHBSS. $1 \mathrm{ml}$ IM (control) or $1 \mathrm{ml}$ aspirin in IM was placed on the monolayer and the Petri dish was incubated with rocking for 30 min at $37^{\circ} \mathrm{C}$. The aspirin or control solution was removed by aspiration and the dish was washed twice with $1.5 \mathrm{ml}$ MHBSS. $1 \mathrm{ml} \mathrm{IM} \mathrm{(control)} \mathrm{or} 1 \mathrm{ml}$ thrombin in IM was placed on the monolayer followed immediately by $0.5 \mathrm{ml}$ untreated or aspirin-treated ${ }^{51} \mathrm{Cr}$-platelets in Tyrode's solution. After rocking for $30 \mathrm{~min}$ at $37^{\circ} \mathrm{C}$, the dish was handled as described above.

In additional studies, before thrombin and platelets were added, the dish was layered with culture medium ( $2 \mathrm{ml} \mathrm{MM}$ 199 with $20 \%$ FCS) and incubated in a $5 \% \mathrm{CO}_{2}$ atmosphere at $37^{\circ} \mathrm{C}$ for various times. The medium was then removed and the monolayer was washed twice with MHBSS. Thrombin and platelets were then added and the dishes were handled as described above.

Electron microscopy studies. After removal of the nonadhering platelets and washing with MHBSS as described above, the monolayer was fixed with $1 \%$ glutaraldehyde in $0.1 \mathrm{M}$ cacodylate buffer ( $\mathrm{pH}$ 7.4) and prepared for scanning electron microscopy according to a slight modification of the procedure described by Kelley et al. $(21,22)$. The tissue was then incubated for 30 min with two changes of $100 \%$ ethanol, dried by the critical point method, coated with carbon and gold, and examined in a scanning electron microscope (Cambridge S4, Cambridge Instrument Co., Inc., Monsey, N. Y.).

Cells to be examined with transmission electron microscopy were fixed on the culture dish with $1 \%$ glutaraldehyde, postfixed in osmium tetroxide, dehydrated in graded alcohol solutions, and embedded in Epon-Araldite (Epon; Shell Chemical Co., Houston, Tex.; Araldite; Ciba-Geigy Corp., Ardsley, N. Y.). Sections were cut with a Reichert ultramicrotome (Reichert Stamping Co., Toledo, Ohio.) and diamond knife (E. I. Dupont de Nemours \& Co., Inc., Wilmington, Del.) and were examined in a Philips EM 300 electron microscope (Philips Electronic Instruments, Inc., Mahwah, N. J.).

Statistical method. Student's $t$ test (23) was employed to determine statistical significance.

\section{RESULTS}

Both untreated and aspirin-treated washed ${ }^{51} \mathrm{Cr}$-platelets aggregated normally with $0.06 \mathrm{U} / \mathrm{ml}$ thrombin. Untreated washed platelets responded to thrombin $(0.5 \mathrm{U} /$ $\mathrm{ml}$ ) by forming MDA in a manner quantitatively similar $\left(3.75 \pm 0.71\right.$ vs. $3.48 \pm 0.39 \mathrm{nmol} \mathrm{MDA} / 10^{9}$ platelets, $P$ $>0.50)$ to platelets separated immediately from the initial platelet-rich plasma. In contrast, washed platelets incubated with $0.1-2.0 \mathrm{mM}$ aspirin showed approximately a $95 \%$ reduction in thrombin-stimulated MDA relative to untreated washed platelets, with values similar to control MDA levels. The controls, which consisted of untreated or aspirin-treated platelets not incubated with thrombin, averaged $0.57 \pm 0.08 \mathrm{nmol}$ $\mathrm{MDA} / 10^{9}$ platelets. This value compares well to the $0.39-0.81-\mathrm{nmol} \mathrm{MDA} / 10^{9}$ platelets range reported by Okuma et al. (24).

In the adherence studies with preformed platelet aggregates (Table I), little adherence of unaggregated ${ }^{51} \mathrm{Cr}$-labeled platelets was seen with endothelial, fibroblast, or smooth muscle cell monolayers, or with empty dishes $(0.5-1.5 \%)$. In contrast, platelets aggregated with $0.068 \mathrm{U} / \mathrm{ml}$ thrombin ( 0.1 total units) adhered significantly to these monolayers as well as to the empty dish. Adherence of the thrombin-induced aggregates to the fibroblasts $(82.1 \pm 0.7 \%)$, smooth muscle cells $(82.9 \pm 0.8 \%)$, and empty dishes $(74.0 \pm 1.2)$ was greater than to the endothelium $(48.5 \pm 5.6 \%)$. This difference was statistically significant $(P<0.01)$. If the thrombinaggregated platelet suspension was incubated with 0.1 $\mathrm{U}$ hirudin in order to neutralize excess thrombin before exposure to the cell monolayer, adherence to endothelium could be reduced approximately $75-90 \%$. No such reduction was observed when the same neutralized 
TABLE I

Adherence to Monolayers of Thrombin-Induced Preformed Platelet

Aggregates Compared with Platelet Adherence to

Thrombin Preincubated Monolayers

\begin{tabular}{|c|c|c|c|c|}
\hline \multirow[b]{2}{*}{ Thrombin } & \multicolumn{4}{|c|}{ Percent platelet adherence* } \\
\hline & Endothelium & Fibroblast & Smooth muscle & Empty dish \\
\hline \multicolumn{5}{|l|}{ Uldish } \\
\hline \multicolumn{5}{|c|}{ Thrombin-induced preformed platelet aggregates $\ddagger$} \\
\hline 0.00 (control) & $1.5 \pm 0.2$ & $0.5 \pm 0.1$ & $0.9 \pm 0.3$ & $0.5 \pm 0.1$ \\
\hline 0.10 & $48.5 \pm 5.6$ & $82.1 \pm 0.7$ & $82.9 \pm 0.8$ & $74.0 \pm 1.2$ \\
\hline \multicolumn{5}{|c|}{ Thrombin preincubated monolayers $\S$} \\
\hline 0.00 (control) & $1.1 \pm 0.1$ & $0.9 \pm 0.2$ & $6.9 \pm 0.6$ & $1.0 \pm 0.1$ \\
\hline 0.04 & $1.4 \pm 0.1$ & $82.0 \pm 1.2$ & $83.7 \pm 0.6$ & $78.6 \pm 0.7$ \\
\hline 0.08 & $1.6 \pm 0.1$ & $84.9 \pm 1.2$ & $84.6 \pm 1.0$ & $81.9 \pm 1.3$ \\
\hline 0.10 & $1.6 \pm 0.1$ & $80.3 \pm 0.8$ & $78.1 \pm 0.7$ & $81.9 \pm 0.3$ \\
\hline 0.50 & $12.5 \pm 4.3$ & $77.6 \pm 0.9$ & $77.6 \pm 0.2$ & $79.0 \pm 0.4$ \\
\hline
\end{tabular}

* Percent adherence was calculated by dividing counts per minute of cells attached to the monolayer after incubation by total counts per minute added to the dish, $\times 100$.

† $0.5 \mathrm{ml}{ }^{51} \mathrm{Cr}$-platelets in Tyrode's solution was stirred in an aggregometer cuvette with $1 \mathrm{ml} \mathrm{IM}$ and then mixed with $25 \mu \mathrm{l} 4 \mathrm{U} / \mathrm{ml}$ bovine thrombin in IM or $25 \mu \mathrm{I}$ IM (control). Aggregated platelets or nonaggregated controls were then transferred from the cuvette to the monolayer dish which was rocked for $30 \mathrm{~min}$ at $37^{\circ} \mathrm{C}$. Data are mean $\pm S E$ from six experiments in duplicate for endothelium, fibroblast, and smooth muscle cells; mean $\pm S E$ from four experiments in duplicate for empty dishes.

$\$ 1 \mathrm{ml}$ bovine thrombin in IM or $1 \mathrm{ml} \mathrm{IM} \mathrm{(control)} \mathrm{was} \mathrm{incubated} \mathrm{with} \mathrm{the}$ monolayer for $5 \mathrm{~min}$ at $37^{\circ} \mathrm{C}$ without rocking. The preincubation solution was left on the monolayer and $0.5 \mathrm{ml}{ }^{51} \mathrm{Cr}$-platelets in Tyrode's was immediately added, the monolayer was then rocked $30 \mathrm{~min}$ at $37^{\circ} \mathrm{C}$. Data are mean $\pm \mathrm{SE}$ from five experiments in duplicate for endothelium and mean $\pm S E$ from two experiments in duplicate for fibroblast and smooth muscle cells and empty dishes.

suspension of aggregates was incubated with empty dishes.

When unaggregated platelets were added to fibroblast and smooth muscle cell monolayers after the monolayers were preincubated with 0.04-0.50 U thrombin (Table I) platelet adherence was similar to that observed with the 0.1-U thrombin-induced preformed aggregates. In contrast, endothelium did not exhibit this platelet adherence even at a thrombin concentration of $0.5 \mathrm{U} /$ dish.

Adherence similar to that obtained with the thrombin preincubated monolayer system (Table I) was also observed if thrombin was added to endothelium, smooth muscle cells, or empty dishes simultaneously with the platelets (Fig. 1, open bars). However, platelet adherence approaching that seen with $0.1 \mathrm{U}$ thrombin-induced preformed platelet aggregates (Table I) could be obtained if the endothelium was first treated for $30 \mathrm{~min}$ with aspirin, washed, and then incubated with thrombin and platelets for an additional $30 \mathrm{~min}$ (Fig. 1, shaded bars). In the absence of thrombin, the usual 1-2\% base-line platelet adherence was found when the endothelium was first treated with 0.1-2.0 $\mathrm{mM}$ aspirin and then incubated with platelets. With $0.08 \mathrm{U}$ thrombin (not shown in Fig. 1), platelet adherence increased to $11.9 \pm 5.0 \%, 28.4 \pm 4.7 \%$, and 38.9 $\pm 5.4 \%$ when endothelium was pretreated with $0.5,1.0$, and $2.0 \mathrm{mM}$ aspirin, respectively. Platelet adherence of $5.4 \pm 0.7 \%, 35.2 \pm 7.7 \%, 44.2 \pm 8.2 \%$, and $47.7 \pm 5.5 \%$ was observed when $0.5 \mathrm{U}$ thrombin and platelets were incubated with $0.1,0.5,1.0$, and $2.0 \mathrm{mM}$ aspirin-treated endothelium. Similar adherence was also observed if the aspirin solution was left on the monolayer and further incubated with thrombin and platelets. This effect of aspirin on endothelium was temporary; the cells recovered in a relatively short time. As indicated in Table II, the capacity of endothelium to inhibit thrombin-induced platelet adherence partially recovered in $30 \mathrm{~min}$ and was almost normal $60 \mathrm{~min}$ after the aspirin was removed and the monolayer was reincubated with the cell culture growth medium.

Similar platelet adherence to both untreated endo- 


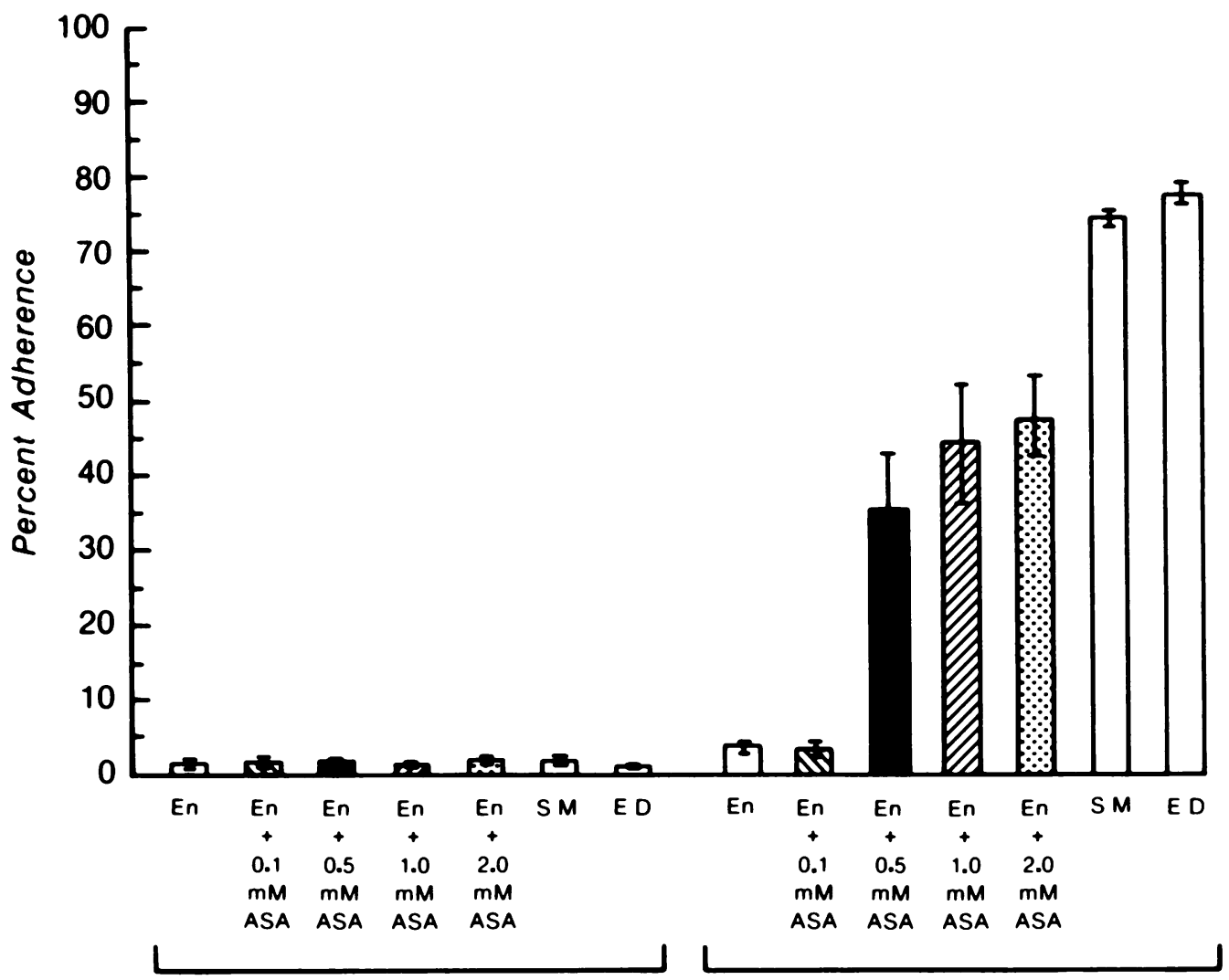

\section{No Thrombin (Control) $\quad 0.5 \cup$ Thrombin}

FIGURE 1 Percent adhering platelets to monolayers of endothelium (En), aspirin (ASA)-treated endothelium, smooth muscle cells (SM), and to empty dishes (ED) when incubated with bovine thrombin and platelets. $1 \mathrm{ml}$ aspirin in $\mathrm{IM}$ or $1 \mathrm{ml} \mathrm{IM}$ was incubated with the monolayer for $30 \mathrm{~min}$ at $37^{\circ} \mathrm{C}$ with rocking. The preincubation solution was removed and the dish was washed twice. $1 \mathrm{ml}$ bovine thrombin in IM or $1 \mathrm{ml} I M$ (control) was added, followed immediately by $0.5 \mathrm{ml}$ untreated ${ }^{51} \mathrm{Cr}$-platelets in Tyrode's solution. The dish was then rocked $30 \mathrm{~min}$ at $37^{\circ} \mathrm{C}$. Percent adherence was calculated by dividing counts per minute of cells attached to the monolayer by total counts per minute added to the dish, $\times 100$. Data are mean $\pm S E$ from three experiments in duplicate for endothelium, and from two experiments in duplicate for smooth muscle cells and empty dish studies.

thelium and aspirin-treated endothelium was observed when various types of thrombin were employed. No significant difference in adherence $(P<0.10)$ was found between the bovine thrombin $(54.3 \pm 2.7 \%)$, which was used for the major portion of this study, and highly purified human thrombins prepared either from citrate $(46.3 \pm 5.0 \%)$ or snake venom $(45.3 \pm 4.0 \%)$ activation of prothrombin. In addition, results were unchanged when adherence studies with untreated or aspirin-treated endothelium were undertaken with platelets pretreated with either low $(0.1 \mathrm{mM})$ or high $(2.0 \mathrm{mM})$ concentrations of aspirin. With platelets treated with $2.0 \mathrm{mM}$ aspirin adherence to untreated smooth muscle cells and empty dishes was also unchanged.
Additional evidence of adherence of platelets to intact endothelium was provided by studies that use scanning and transmission electron microscopy. Examples are shown in Figs. 2 and 3. Platelet aggregates remained attached to the endothelial monolayer, despite several washings, when preformed thrombin-induced aggregates were added to the monolayer or when unaggregated platelets were incubated with the endothelial monolayer after it had been exposed to thrombin. Transmission electron microscopy showed that aggregates of degranulated platelets adhered to the intact endothelium (Fig. 4) without ultrastructural evidence of damage to the plasma membrane of the endothelial cell. No evidence of polymerized fibrin was seen at the sites of attachment. 
TABLE II

Platelet Adherence: Duration of the Aspirin Effect on Endothelium

\begin{tabular}{llccc}
\hline & & & \multicolumn{2}{c}{ Percent platelet adherencet } \\
\cline { 3 - 5 } Monolayer & ASA & $\begin{array}{c}\text { Recovery } \\
\text { period* }^{*}\end{array}$ & $\begin{array}{c}\text { No thrombin } \\
\text { (control) }\end{array}$ & $\begin{array}{c}\text { Bovine thrombin } \\
(0.5 \mathrm{U})\end{array}$ \\
\hline & $m M$ & $\min$ & & \\
Endothelium & 0 & 0 & $2.2 \pm 0.3$ & $2.4 \pm 0.1$ \\
Endothelium & 1.0 & 0 & $2.3 \pm 0.2$ & $39.6 \pm 7.4$ \\
Endothelium & 1.0 & 15 & $2.0 \pm 0.3$ & $29.7 \pm 8.1$ \\
Endothelium & 1.0 & 30 & $1.8 \pm 0.4$ & $12.9 \pm 4.0$ \\
Endothelium & 1.0 & 60 & $2.0 \pm 0.4$ & $5.1 \pm 1.1$ \\
\hline
\end{tabular}

$1 \mathrm{ml}$ aspirin (ASA) in IM or $1 \mathrm{ml} \mathrm{IM}$ was incubated with the monolayer for $30 \mathrm{~min}$ at $37^{\circ} \mathrm{C}$ with rocking. The preincubation solution was removed and the dish was washed twice. The designated ASA-treated monolayers were layered with $2 \mathrm{ml}$ growth medium (MM-199 with 20\% FCS), incubated in a $5 \% \mathrm{CO}_{2}$ atmosphere at $37^{\circ} \mathrm{C}$ for the indicated times, and rewashed twice. $1 \mathrm{ml} 0.5 \mathrm{U} / \mathrm{ml}$ bovine thrombin in IM, or $1 \mathrm{ml} \mathrm{IM} \mathrm{(control)} \mathrm{was} \mathrm{added} \mathrm{to} \mathrm{all} \mathrm{dishes,} \mathrm{fol-}$ lowed immediately by $0.5 \mathrm{ml}$ untreated ${ }^{51} \mathrm{Cr}$-platelets in Tyrode's solution. The dish was then rocked $30 \mathrm{~min}$ at $37^{\circ} \mathrm{C}$. * The time that the aspirin-treated monolayer was reincubated with the growth medium.

† Percent adherence was calculated by dividing counts per minute of cells attached to the monolayer by total counts per minute added to the dish, $\times 100$. Data are mean $\pm S E$ from three experiments in duplicate.

\section{DISCUSSION}

In the absence of aggregating agents we have observed little adherence of platelets to monolayers of venous endothelium, arterial fibroblasts or smooth muscle cells, or empty dish controls. This observation is in agreement with Booyse et al. (10) who reported no interaction between normal, undamaged, bovine aortic endothelial monolayers and ${ }^{125}$ I-labeled bovine platelets. When platelets were preaggregated with thrombin (Table I), adherence to the monolayers was observed but adherence to endothelium was significantly less $(P<0.01)$ than to fibroblast or smooth muscle cells, or to empty dishes. This difference, which is based on adherence of platelets to confluent cell monolayers with a surface area of $962 \mathrm{~mm}^{2}$, is further magnified if the cell count variation between endothelium (7-8 $\times 10^{5}$ cells per $\left.962 \mathrm{~mm}^{2}\right)$, fibroblast $\left(3-4 \times 10^{5}\right)$, and smooth muscle cells $\left(5-7 \times 10^{5}\right)$ is taken into consideration. With thrombin-induced preformed platelet aggregate adherence to endothelium, the role of thrombin is complex and may be effecting both platelets and endothelium. This is suggested by studies in which adherence to endothelium was reduced $75-90 \%$ when the thrombin-aggregated platelet suspension was exposed to hirudin. Hirudin, employed in a quantity sufficient to inhibit the amount of thrombin used to ag- gregate the platelets, was added to the thrombin aggregated platelet suspension before the aggregates were added to the endothelium. This is in marked contrast to the adherence of thrombin-induced preformed aggregates to the empty dish control in which previous hirudin neutralization of excess thrombin did not diminish the thrombin-induced adherence of preformed platelet aggregates.

The adherence of platelets to cell monolayers which had been pretreated with thrombin and then exposed to unaggregated platelets in the presence of the thrombin preincubation solution (Table I) was undertaken to help interpret the role of thrombin in adherence by providing a thrombin dose-response curve with the various monolayers. Maximal platelet adherence to fibroblast and smooth muscle cells, and empty dishes was quantitatively similar to that found with platelets preaggregated with thrombin. In contrast, thrombininduced adherence to endothelium was less, even at higher thrombin concentrations, than that seen with 0.1 $\mathrm{U}$ thrombin-preformed aggregates. Platelet adherence to monolayers preincubated with $0.5 \mathrm{U}$ thrombin was $12.5 \%$ although that of $0.1 \mathrm{U}$ thrombin preformed platelet aggregates was $48.5 \%$.

These findings support the concept that the endothelium is relatively nonthrombogenic in comparison with other cell types. This characteristic may involve heparins on the endothelial cell surface $(25,26)$, the reactivity of the plasma membrane, and the production of inhibitors. In earlier studies, Saba and Mason (27) and Saba et al. (28), suggested that an inhibitor of platelet aggregation was produced in endothelium and could be released by the addition of aggregating agents. Harker et al. (29) found a similar inhibitor of platelet function. Possibly involved in both cases is prostaglandin $\mathrm{I}_{2}\left(\mathrm{PGI}_{2}\right.$ or prostacyclin) (30), a potent inhibitor of platelet aggregation probably produced in the vascular intima from prostaglandin endoperoxides (31). Weksler et al. (32) have recently shown that endothelial cells cultured from the human umbilical cord vein do have the capacity to synthesize $\mathbf{P G I}_{2}$. In studies using a radioimmunoassay for 6-keto-prostaglandin $F_{1 \alpha}$, the stable end product of $\mathrm{PGI}_{2}$, we have found that cultured endothelial cells but not our fibroblast or smooth muscle cells yield 6-keto-prostaglandin $F_{1 \alpha}$ in response to thrombin. ${ }^{2}$ Whether $\mathrm{PGI}_{2}$ is involved in the modification of thrombin-induced platelet adherence cannot be proven from the present work; additional studies are required to delineate this possibility.

A possible factor which could influence the difference in the adherence qualities between endothelium and the other cell types used in this study was that the fibroblasts and smooth muscle cells were passed

${ }^{2}$ Smith, J. B., J. C. Hoak, and R. L. Czervionke. To be published. 


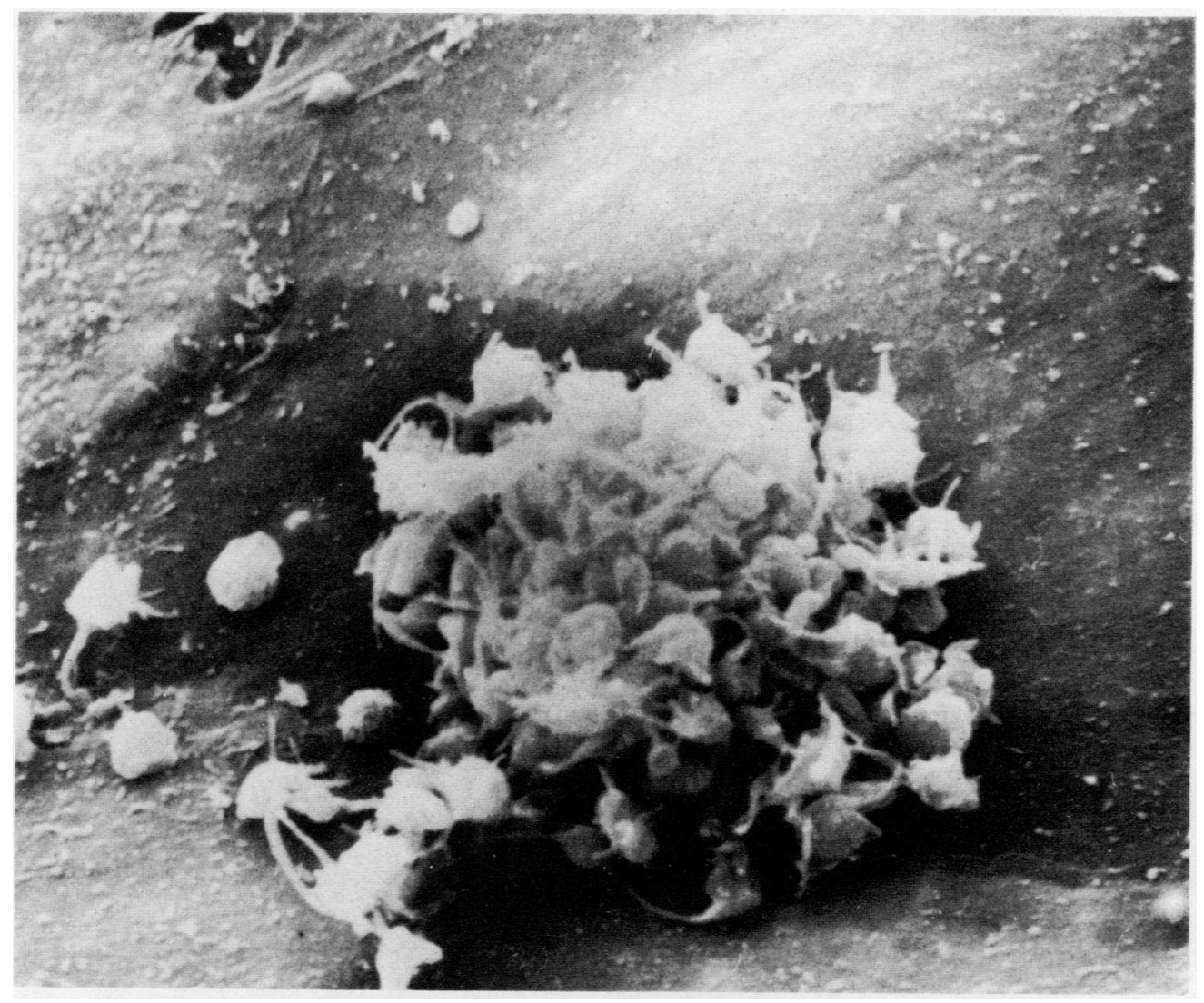

FIGURE 2 Scanning electron micrograph of a thrombin-induced platelet aggregate which was adherent to the monolayer of the cultured endothelial cells. Magnification, $\times 2,600$.

cultures (5th-14th passage) although primary endothelial cultures were employed. This is unlikely to be a major factor because Essien et al. have found results comparable to ours using fresh tissues from the aorta of experimental animals. Thrombin caused adherence of platelets to the intact endothelium but caused even greater adherence to subendothelial tissues. ${ }^{3}$

Pretreatment of the endothelium (Fig. 1) and platelets with aspirin gave results of particular interest. It is known that the endothelium can produce $\mathrm{PGI}_{2}(32)$, the inhibitor of platelet aggregation which is postulated to represent a key factor normally responsible for the nonthrombogenic properties of the vascular intima ( 30 , 31 ). Because aspirin blocks the cyclooxygenase activity in platelets which is responsible for the generation of endoperoxides involved in thromboxane formation (33), it may also exert a similar effect on the endothelial cell and inhibit the production of $\mathrm{PGI}_{2}$.

In the present study our results suggest that aspirin

\footnotetext{
${ }^{3}$ Personal communication concerning manuscript in preparation. Essien, E. M., J. P. Cazenave, S. Moore, and J. F. Mustard. Effect of heparin and thrombin on platelet adherence to the surface of rabbit aorta.
}

treatment of platelets had no effect on their adherence by thrombin. It should be noted that 0.1-2.0 mM aspirin-treated washed platelets in Tyrode's solution aggregated normally with thrombin but were inhibited by $95 \%$ in their ability to produce MDA. A $95 \%$ decrease in platelet MDA production by aspirin at a concentration of $0.01-0.10 \mathrm{mM}$ has also been observed by Baenziger et al. (34). MDA production is reported to correlate with platelet cyclooxygenase activity (33, 35). However, a decrease in MDA production need not result only from decreased production of endoperoxides by the cyclooxygenase, but could also result from increased production of other endoperoxide products which do not break down into MDA (36).

The effect of aspirin on adherence was upon the endothelium; the inhibitory properties of these cells could be decreased to the degree that platelet adherence approached that observed with smooth muscle cells and the empty dish control (Fig. 1). Note that in the absence of thrombin only base-line adherence was observed with the aspirin-treated monolayers. In contrast, in the presence of thrombin, adherence above base line and nonaspirin-treated endothelium was obtained with endothelial cell monolayers pretreated 


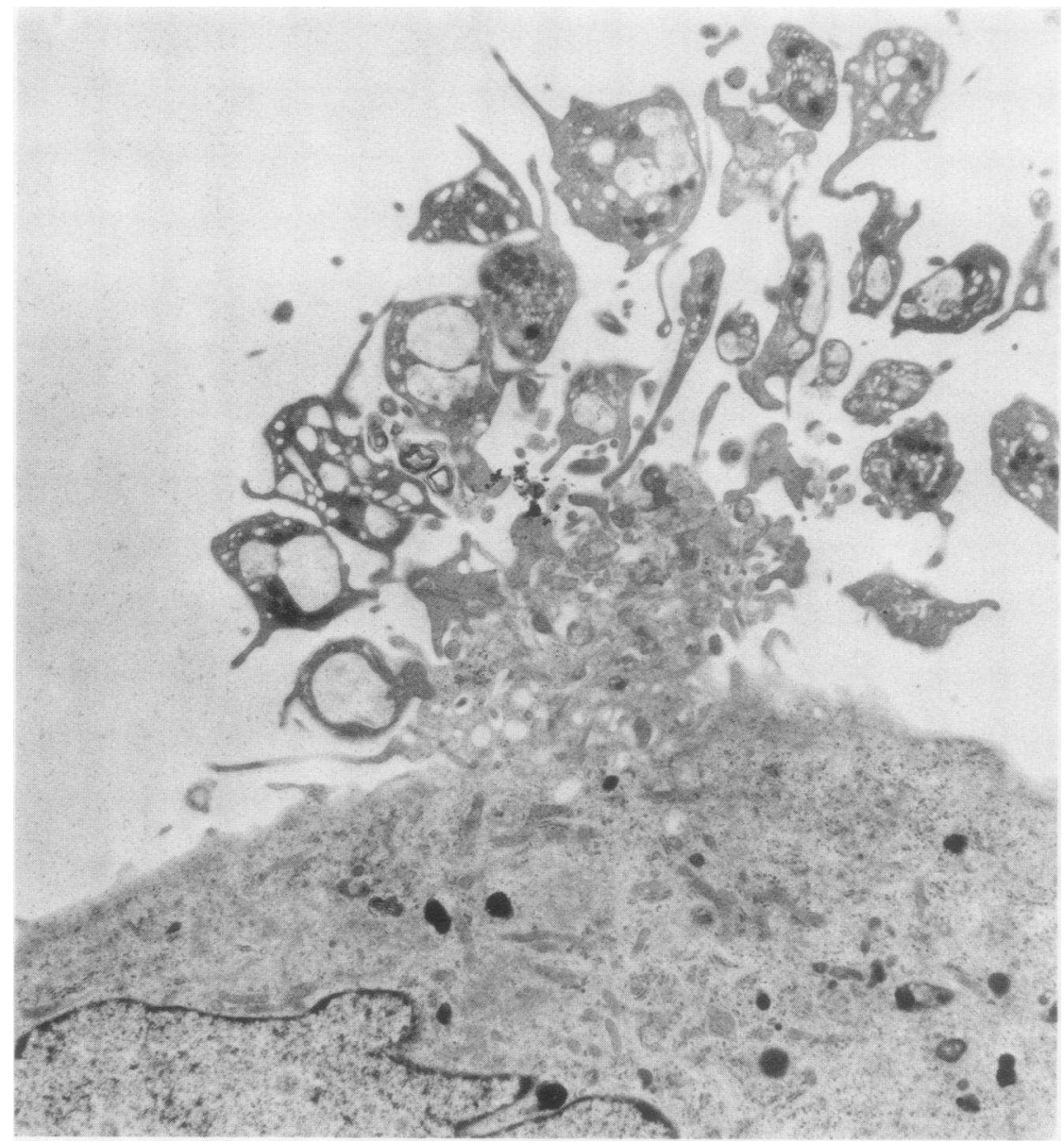

FIGURE 3 Transmission electron micrograph of a thrombin-induced platelet aggregate attached to a cultured endothelial cell. Magnification, $\times 5,586$.

with aspirin at $0.5-2.0 \mathrm{mM}$. At $0.5 \mathrm{U}$ thrombin adherence increased from the $5-10 \%$ value associated with nonaspirin-treated endothelium and approached the $50 \%$ level by pretreating the monolayer with $2.0 \mathrm{mM}$ aspirin. Also note that $0.1 \mathrm{mM}$ aspirin is sufficient to block $0.5 \mathrm{U}$ thrombin-induced platelet MDA production but it does not interfere with the inhibitory effect of the endothelium. Pharmacologically, this 0.1$\mathrm{mM}$ aspirin concentration $\cong$ to the $0.12 \mathrm{mM}$ plasma concentration of unchanged aspirin observed $15 \mathrm{~min}$ after the ingestion of $650 \mathrm{mg}$ aspirin (two 5-grain tablets) (37) or $30 \mathrm{~min}$ after the ingestion of $1,300 \mathrm{mg}$ aspirin (38). These plasma aspirin concentrations are $68 \%$ of that observed when the same dose is given intravenously (37). Together, these data suggest that the endothelial adherence observations which involve $30-\mathrm{min}$ incubations with $0.5-2.0 \mathrm{mM}$ aspirin (Fig. 1) may have physiological significance only in situations involving prolonged or chronic use of high doses of aspirin.

In contrast to its effect on platelet function (39-41), the ability of aspirin to abolish endothelial cell inhibition to thrombin-induced platelet adherence is temporary. As shown in Table II, aspirin-treated endothelium almost completely recovers its capacity to inhibit adherence if placed in fresh growth medium for only $1 \mathrm{~h}$ before the incubation with thrombin and platelets. Villa and de Gaetano (42) have also noted a temporary, but longer-lasting effect of aspirin in in vivo studies with rat vascular tissue.

Altogether, these data indicate that aspirin has an effect on the endothelium and can enhance platelet adherence if small amounts of thrombin are present. Such effects may help to explain the relatively slight impairment of clinical hemostasis caused by aspirin therapy despite profound alterations in platelet function measured with in vitro tests.

In determining the physiological significance of the platelet adherence observations reported in this study limitations of this and any in vitro model system should be considered. Although platelets were kept in a con- 


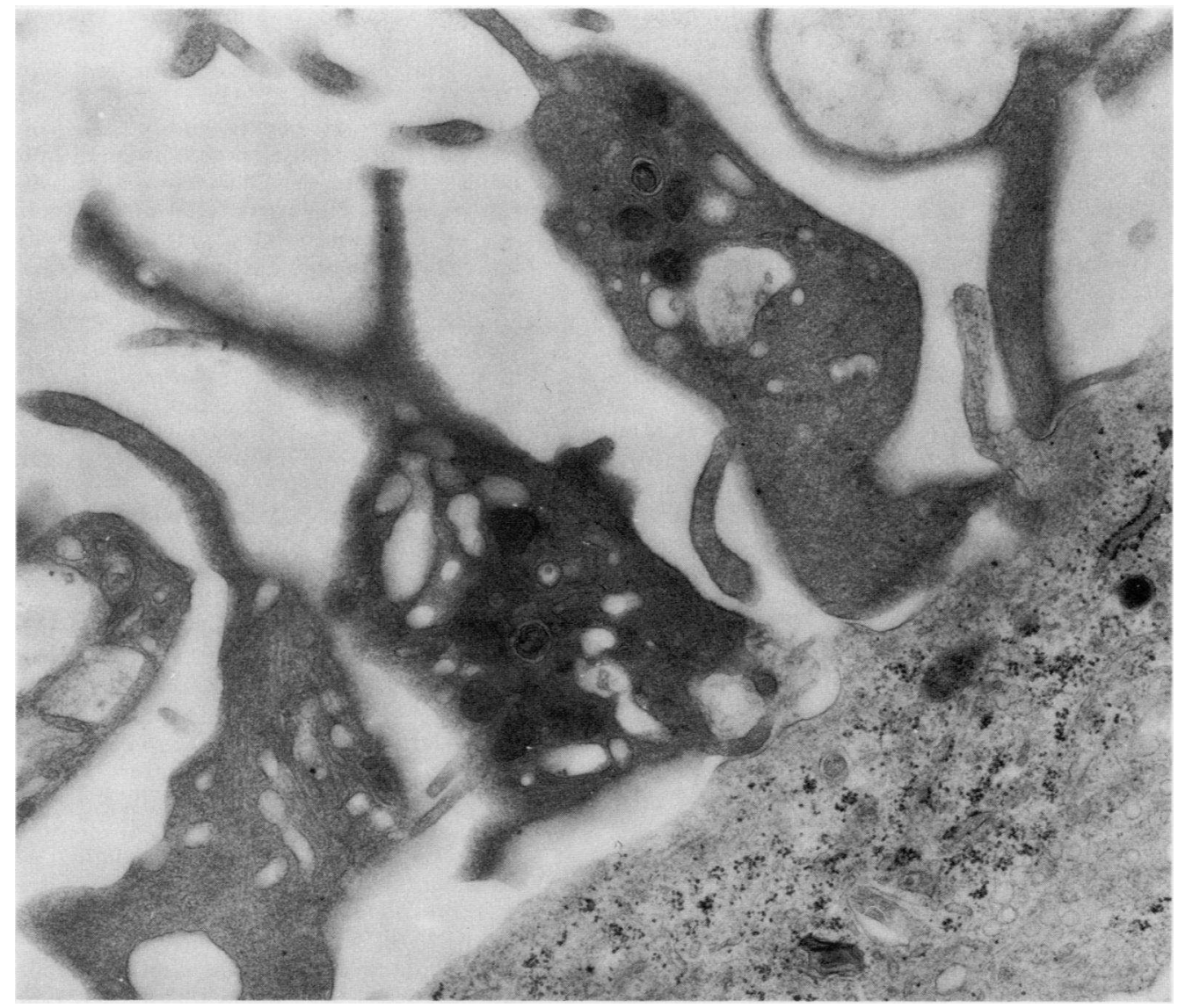

FIGURE 4 Transmission electron micrograph which shows sites of attachment of thrombintreated platelets to the endothelial cell. Magnification, $\times 21,945$.

stant rocking motion, this cannot be assumed to represent the type of shear stress and flow exhibited in a pulsatile arterial system. Likewise, the limitation necessitated by use of cells from tissue culture is always a consideration. Even if primary endothelial cultures are representative of the in vivo situation, it is still not known whether human umbilical vein endothelial cells are representative of their adult counterparts. Even with these restrictions, our observations have implications for the mechanisms which operate in platelet interactions with cellular components of the blood vessel wall.

\section{ACKNOWLEDGMENTS}

We are grateful for the valuable technical assistance of Ms. Carol Bray, Donna Haycraft, and Connie Schroeder and to Dr. Whyte Owen for providing us with human thrombin.

This work was supported in part by the National Heart, Lung, and Blood Institute through a Specialized Center of Research in Atherosclerosis, grant 14230.

\section{REFERENCES}

1. Baumgartner, H. R., M. B. Stemerman, and T. H. Spaet. 1971. Adhesion of blood platelets to subendothelial sur- face: distinct from adhesion to collagen. Experientia (Basel). 27: 283-285.

2. Stemerman, M. B., H. R. Baumgartner, and T. H. Spaet. 1971. The subendothelial microfibril and platelet adhesion. Lab. Invest. 24: 179-186.

3. Stemerman, M. B., and T. H. Spaet. 1972. The subendothelium and thrombogenesis. Bull. N. Y. Acad. Med. 48: 289-301.

4. Baumgartner, H. R. 1973. The role of blood flow in platelet adhesion, fibrin deposition, and formation of mural thrombi. Microvasc. Res. 5: 167-179.

5. Cazenave, J. P., M. A. Packham, M. A. Guccione, and J. F. Mustard. 1975. Inhibition of platelet adherence to damaged surface of rabbit aorta. J. Lab. Clin. Med. 86: $551-563$

6. Dosne, A. M., L. Drouet, and E. Dassin. 1976. Usefulness of ${ }^{51} \mathrm{Cr}$-platelet labelling for the measurement of platelet deposition on subendothelium. Microvasc. Res. 11: 111114.

7. Lough, J., and S. Moore. 1975. Endothelial injury induced by thrombin or thrombi. Lab. Invest. 33: 130-135.

8. Rafelson, M. E., Jr., T. P. Hoveke, and F. M. Booyse. 1973. The molecular biology of platelet-platelet and platelet-endothelial interactions. Ser. Haematol. 6: 367-381.

9. McDonald, R. I., D. Shepro, M. Rosenthal, and F. M. Booyse. 1973. Properties of cultured endothelial cells. Ser. Haematol. 6: 469-478.

10. Booyse, F. M., S. Bell, B. Sedlak, and M. E. Rafelson. 
1975. Development of an in vitro vessel wall model for studying certain aspects of platelet-vessel (endothelial) interactions. Artery. 1: 518-539.

11. Winkelhake, J. L., and G. L. Nicolson. 1976. Determination of adhesive properties of variant metastatic melanoma cells to BALB/3T3 cells and their virus-transformed derivatives by a monolayer attachment assay.J. Natl. Cancer Inst. 56: 285-291.

12. Awbrey, B. J., W. G. Owen, G. L. Fry, F. H. Cheng, and J. C. Hoak. 1975. Binding of human thrombin to human endothelial cells and platelets. Blood. 46: 1045. (Abstr.)

13. Mustard, J. F., D. W. Perry, N. G. Ardlie, and M. A. Packham. 1972. Preparation of suspensions of washed platelets from humans. Br. J. Haematol. 22: 193-204.

14. Jaffe, E. A., R. L. Nachman, C. G. Becker, and C. R. Minick. 1973. Culture of human endothelial cells derived from umbilical veins. Identification by morphologic and immunologic criteria. J. Clin. Invest. 52: 2745-2756.

15. Ross, R. 1971. The smooth muscle cell. II. Growth of smooth muscle in culture and formation of elastic fibers. J. Cell Biol. 50: 172-186.

16. Gimbrone, M. A., and R. S. Cotran. 1975. Human vascular smooth muscle in culture. Growth and Ultrastructure. Lab. Invest. 33: 16-27.

17. Aster, R. H., and J. H. Jandl. 1964. Platelet sequestration in man. I. Methods. J. Clin. Invest. 43: 843-855.

18. Stuart, M. J., S. Murphy, and F. A. Oski. 1975. A simple nonradioisotope technic for the determination of platelet life-span. N. Engl. J. Med. 292: 1310-1313.

19. Lowry, O. H., N. J. Rosebrough, A. L. Farr, and R. J. Randall. 1951. Protein measurement with the Folin phenol reagent. J. Biol. Chem. 193: 265-275.

20. Marcus, A. J., and M. B. Zucker. 1965. The Physiology of Blood Platelets. Grune and Stratton, Inc., New York. 1.

21. Kelley, R. O., R. A. F. Dekker, and J. G. Bluemink. 1973. Ligand-mediated osmium binding: its application in coating biological specimens for scanning electron microscopy. J. Cell Biol. 59: 165a. (Abstr.)

22. Kelley, R. O., R. A. F. Dekker, and J. Bluemink. 1973. Ligand-mediated osmium binding: its application in coating biological specimens for scanning electron microscopy. J. Ultrastruct. Res. 45: 254-258.

23. Hill, A. B. 1961. Principles of Medical Statistics. The Lancet, Ltd., London. 7th edition. 146-149.

24. Okuma, M., M. Steiner, and M. G. Baldini. 1971. Studies on lipid peroxides in platelets. J. Lab. Clin. Med. 77: 728-742.

25. Buonassisi, V., and M. Root. 1975. Enzymatic degradation of heparin-related mucopolysaccharides from the surface of endothelial cell cultures. Biochim. Biophys. Acta. 385: $1-10$.

26. Wasteson, A., B. Glimelius, C. Busch, B. Westermark, C. H. Heldin, and B. Norling. 1977. Effect of a platelet endoglycosidase on cell surface associated heparin sulphate of human cultured endothelial and glial cells. Throm. Res. 11: 309-321.
27. Saba, S. R., and R. G. Mason. 1974. Studies of an activity from endothelial cells that inhibits platelet aggregation, serotonin release, and clot retraction. Thromb. Res. 5: 747-757.

28. Saba, S. R., W. H. Zucker, and R. G. Mason. 1973. Some properties of endothelial cells isolated from human umbilical cord vein. Ser. Haematol. 6: 456-468.

29. Harker, L. A., N. Joy, R. T. Wall, L. Quadracci, and G. Striker. 1977. Inhibition of platelet reactivity by endothelial cells. Thrombos. Haemostasis. 38: 137. (Abstr.)

30. Moncada, S., S. Gryglewski, S. Bunting, and J. R. Vane. 1976. An enzyme isolated from arteries transforms prostaglandin endoperoxides to an unstable substance that inhibits platelet aggregation. Nature (Lond.). 263: 663-665.

31. Moncada, S., E. A. Higgs, and J. R. Vane. 1977. Human arterial and venous tissues generate prostacyclin (Prostaglandin X), a potent inhibitor of platelet aggregation. Lancet. I: $18-21$.

32. Weksler, B. B., A. J. Marcus, and E. A. Jaffe. 1977. Synthesis of prostaglandin $\mathrm{I}_{2}$ (prostacyclin) by cultured human and bovine endothelial cells. Proc. Natl. Acad. Sci. U. S. A. 74: 3922-3926.

33. Roth, G. J., N. Stanford, and P. W. Majerus. 1975. Acetylation of prostaglandin synthase by aspirin. Proc. Natl. Acad. Sci. U. S. A. 72: 3073-3076.

34. Baenziger, N. L., M. J. Dillender, and P. W. Majerus. 1977. Cultured human skin fibroblasts and arterial cells produce a labile platelet-inhibitory prostaglandin. Biochem. Biophys. Res. Commun. 78: 294-301.

35. Rome, L. H., W. E. M. Lands, G. J. Roth, and P. W. Majerus. 1976. Aspirin as a quantitative acetylating reagent for the fatty acid oxygenase that forms prostaglandins. Prostaglandins. 11: 23-30.

36. Smith, J. B., C. M. Ingerman, and M. J. Silver. 1976. Malondialdehyde formation as an indicator of prostaglandin production by human platelets. J. Lab. Clin. Med. 88: $167-172$.

37. Rowland, M., S. Riegelman, P. A. Harris, and S. D. Sholkoff. 1972. Absorption kinetics of aspirin in man following oral administration of an aqueous solution. J. Pharm. Sci. 61: 379-385.

38. Lange, W. E., and S. A. Bell. 1966. Fluorometric determination of acetylsalicylic acid and salicylic acid in blood. J. Pharm. Sci. 55: 386-389.

39. Burch, J. W., N. Stanford, and P. W. Majerus. 1978. Inhibition of platelet prostaglandin synthetase by oral aspirin. J. Clin. Invest. 61: 314-319.

40. O'Brien, J. R. 1968. Effect of salicylates on human platelets. Lancet. I: 779-783.

41. Weiss, H. J., L. M. Aledort, and S. Kochwa. 1968. The effect of salicylates on the hemostatic properties of platelets in man. J. Clin. Invest. 47: 2169-2180.

42. Villa, S., and G. de Gaetano. 1977. Prostacyclin-like activity in rat vascular tissues. Fast, long-lasting inhibition by treatment with lysine acetylsalicylate. Prostaglandins. 14: $1117-1124$ 